Journal of Mathematics and Informatics

Vol. 14, 2018, 17-26

ISSN: 2349-0632 (P), 2349-0640 (online)

Published 21 August 2018

www.researchmathsci.org

DOI: http://dx.doi.org/10.22457/jmi.v14a3

Journal of

Mathematics and

Informatics

\title{
Research on Information Adoption Behavior in Virtual Communities Based on the Information Ecology Theory
}

\author{
Yi Peng ${ }^{1}$, Liang-ru $\mathbf{Y u}^{2}$ and Dong-xue Xie ${ }^{3}$ \\ ${ }^{1}$ School of Economics and Management \\ Chongqing University of Posts and Telecommunications \\ Chongqing - 400065, Chongqing, China. E-mail: 635644882@qq.com \\ ${ }^{2}$ School of Economics and Management \\ Chongqing University of Posts and Telecommunications \\ Chongqing - 400065, Chongqing, China. E-mail: yuliangru@qq.com \\ ${ }^{3}$ School of Economics and Management \\ Chongqing University of Posts and Telecommunications \\ Chongqing - 400065, Chongqing, China. E-mail: 3338468665@qq.com
}

Received 8 July 2018; accepted 15 August 2018

Abstract. Based on the theory of information ecology, this paper explores factors that sinfluence users' information adoption behavior in virtual communities. It combines three core elements in information ecology: information, information man, and information environment. Using data collected from 401 users in virtual communities to conduct a hypothesis testing, the empirical results show that 1) usefulness has a direct positive effect on information adoption; 2) interaction of trust and security has a positive effect on information adoption.

Keywords: information adoption; virtual communities; information ecology theory; empirical study

\section{AMS Mathematics Subject Classification (2010): 92D40}

\section{Introduction}

The contact between an ecological concept and information environment is expressed by the information ecology [1]. With the increasing importance and complexity of the information environment, information ecology has gained a significant existential value.

Nardi and O'Day defined information ecology as a system composed of people, practices, values, and technology in a certain environment [2]. They discussed the relationship between IT and human beings in this environment, noting that the human activity served by technology is more important than the technology itself. Other scholars claim that information is the sum of ecological factors and their relationship to each other within a certain range of information resources [3]; the sum of the relationship between information, people, and the environment [4]; and an integrity formed by the process of communication and circulation of information between people, organizations, and communities in a certain space [5]. This paper argues that, under the information ecology theory, information, information man, and information environment are correlated and 


\section{Yi Peng, Liang-ru Yu and Dong-xue Xie}

balanced. On one hand, information environment affects and restricts the information man; it plays an important role in their activities and the development of their relation. On the other hand, the information man's emotions and cognitions of information are critical to its quality and value.

With the advance of information technology, virtual communities have become important places in this information ecology. Nowadays, different types of virtual communities appear in our networks, such as interest-specific, relationship, entertainment, and commerce communities, among many others. Virtual communities, as indispensable platforms for information flowing and sharing, have enhanced the social contact of users [6], realized user self-efficacy [7], and allowed users acquiring information to meet their needs [8].

Information adoption is a process wherein people can purposefully utilize information [9]. It connects information pursuit, choice, search, and utility, which makes each part of artificially differentiated information behavior more complete and reasonable. It reflects characteristics of integrity, relevance, and structure between each component of information behavior [10]. Information adoption in this paper refers to a behavior of information absorption and utilization after activities-such as information pursuit, choices, analysis, assessment, and so forth-are conducted in virtual communities. This behavior is a kind of principal activity that the user intends to conduct in the virtual community [9]. It can promote the development of virtual communities, accelerate the speed of information transmission, and have a positive effect on users as well.

Information adoption is one of the most important behaviors in virtual communities, as it is a driving force in the exchange of information, to share information, and to establish social connections. In the human-centered virtual communities, users' information adoption allows users to meet their needs and realize their values; it forms the core of virtual communities as well. However, influencing factors of information adoption need further exploration. Therefore, this paper is of important theoretical and practical significance.

\section{Literature review}

Previous studies have researched information adoption from different perspectives. Shi and Mao researched the impact of information adoption behavior in public crisis on crisis information dissemination [11]. Xiang et al. examined perceived information quality is the key factor to information adoption attitude [12]. Lee and Yang analyzed information adoption on the basis of reviews for online products from new product developers [13]. By having established a research model, Cheung elaborated the impact of electronic word-of-mouth on information adoption in online customer communities [14]. Nguyen and Western, by establishing a social-structural framework, and using data from a national survey of 4,270 Australians, elaborated the factors influencing the adoption of online news and information [15].

Few studies research information adoption considering influencing factors from information, user and environment. However, these three factors, information, user and environment, have important influence on information adoption, making it necessary to study them together. In terms of researching variety, in literature, researchers rarely analyze user actions by applying both main and interaction effects. However, in the 


\section{Research on Information Adoption Behavior in Virtual Communities Based on the Information Ecology Theory}

virtual community, it is a likely existing link among user action factors-these factors could thus have an impact on information adoption. Therefore, a comprehensive discussion requires a combination of main and interaction effects.

Unlike extant literature, our research 1) considers the virtual community a situation, thereby providing a clear explanation of information adoption behavior; 2) discusses factors influencing information adoption in the virtual community using three elementsinformation, information man, and information environment-based on the information ecology theory; and 3) combines the main and interaction effects to analyze information adoption, and finally establish a research model from the perspective of information ecology.

\section{Hypotheses}

From the perspective of information ecology, information adoption is influenced by information, information man, and information environment. This paper argues that the most important factor of information is usefulness, the most important factor of information man is trust, and the most important factor of information environment is security.

\subsection{Information}

From the angle of information elements, this paper emphasizes the usefulness of information. This usefulness means the integrity and accuracy of information that can be exploited by users toward producing good results. The usefulness, reflecting the value of information [16], may bring benefits to users. Thus, it can stimulate users' desires to adopt information, and has become a main motive of users' information adoption. Therefore, this paper puts forward the following hypothesis:

H1: The usefulness has a positive effect on information adoption.

\subsection{Information man}

Information man in this paper refers to users in virtual communities. From the angle of information man, trust among information men is emphasized. Trust, reflecting users' comprehensive evaluation to another user's behavior and ability, can usually be regarded as a decision-support tool. It is used for the analysis of relevantly reliable information sources, especially from a reliable source to seek advices and make decisions [17,18]. In a virtual community centered on people, behaviors and activities of users are built on the basis of trust. Trust is an important condition of information adoption. Information will appear more credible when a user believes that other users will not send false information, and may bring their help. In this way, users will hold a clearer attitude toward information adoption. Therefore, this paper proposes the following hypothesis:

H2: Trust has a positive effect on information adoption.

\subsection{Information environment}

As for information environment, this paper emphasizes the security of information environment. Security, including network security, information security, and users' 


\section{Yi Peng, Liang-ru Yu and Dong-xue Xie}

security, means users' privacy and sensitive content in the virtual community are under protection. They are protected from various internal and external dangers, threats, harm, and misleading information. Information adoption is affected by the security of a virtual community. The safety of the virtual community can reduce the possibility of the occurrence of risks, so that users can adopt more accurate and complete information to promote the production of information adoption. Therefore, the following hypothesis is presented in this paper:

H3: Security has a positive effect on information adoption.

\subsection{Interaction effect}

The usefulness of information and the trust of the information man may have interaction effects. Useful information can give users good results, which can strengthen users' trust toward other users' qualities and abilities; it improves trust among users. Meanwhile, trust among users can encourage them to share high quality information, thereby enhancing the value and improving the usefulness of the information. The mutual combination of information usefulness and users' trust stimulates their information adoption. As a result, this paper raises the following hypothesis:

H4: The interaction of usefulness and trust has a positive effect on information adoption.

Interaction effect may exist in the usefulness of information and the security of information environment. On one hand, the usefulness decreases the distortion and incompleteness of information, reduces information risks, and further improves the security of information environment. On the other hand, a safe information environment can ensure information security, which would then avoid information asymmetry, information pollution, and so forth, thus making more useful information available. The combination of information availability and security of the information environment provides a more powerful support for the users' information adoption behavior. Therefore, the following hypothesis is made in this paper:

H5: The interaction of usefulness and security has a positive effect on information adoption.

There may be an interaction between the trust of information man and the security of information environment. Trust, as a kind of internal cognitive capability, helps reduce internal risks in the form of misunderstanding, fraud, and infringement among users. This lowers the possibility of external risks, while improving the security of the information environment. At the same time, a secured information environment serves to resist external risks caused by misunderstanding, infringement, threats, and other similar forms, so that the relationship among users is under protection and the degree of trust among them is accordingly improved. It will be better to promote both users' information adoption if the trust of the information man and the security of information environment are combined. Therefore, the following hypothesis is made in this paper:

H6: The interaction of trust and security has a positive effect on information adoption. 


\section{Research on Information Adoption Behavior in Virtual Communities Based on the Information Ecology Theory}

\section{Methods}

\subsection{Measures}

We measured information adoption with three items. The information adoption scale is developed by revising Song [19]'s scale, which makes it fit the context of virtual communities. Responses were marked on a 5 -point Likert scale ranging from $1=$ very inconsistent to $5=$ very consistent, and all items were reverse scored.

As for information factors, the usefulness scale (three items) was sourced from Cheung [14]'s scale. In terms of the factors of the information man, we measured trust (three items) using scales that were sourced from Gefen et al. [20], Luo [21], and Chiu et al. [6]. With respect to factors of information environment, the security scale (three items) was sourced from Wang [22]'s scale.

In addition, gender, age, and level of education were used as control variables, following Hsu and Walter [23] and Seyedghorban et al. [24]. We also controlled for Internet experience and occupation. Since Internet experience has an impact on users' online behavior [25], their occupation might also influence their online behavior.

The first draft of the questionnaire was discussed multiple times by members of the research group; relevant experts were also consulted. A revised version is used for the formal survey.

\subsection{Sample}

Using a computer program, we randomly selected 2,580 users from among 2.6 million people in the sample bank of a professional online survey firm chosen by many Chinese research institutes and firms. We sent users an online questionnaire through email, push notifications, and other similar distribution methods. Before beginning the survey, participants were informed of the purpose of the study and method of data usage. They were then able to exit the survey if they were not willing to take part in this study. Four hundred and forty-nine surveys were returned (the return rate is $17.40 \%$ ) after a rejection of invalid responses (such as insufficiency in answer time, wrong keys in a trap question, obvious regularities in responses, and low frequencies in using a virtual community), and eventually 401 valid responses were collected (validity rate is $89.31 \%$ ). Of them, with 195 respondents, men account for $38.63 \%$, and with 206 respondents, women accounted for $51.37 \%$. In terms of age, the percentages of the age groups (19-25, 26-35, 36-45, and above 45 ) are $9.98 \%, 71.07 \%, 16.96 \%$ and $2.00 \%$ respectively. Among all popular virtual communities, the usage rates of Baidu Tieba and Weibo were relatively high: $79.05 \%$ and $77.81 \%$, respectively. The usage rates of other common virtual communities, including QQCLUB, Tianya Community, Douban, and Zhihu were 47.88\%, 46.63\%, 36.91\%, and $34.41 \%$, respectively. Furthermore, $93.02 \%$ of the respondents had more than one year of experience in using virtual communities. As for the usage frequency, most respondents used them once a day, with a percentage of $52.37 \%$.

\section{Results}

We conducted a reliability analysis to confirm the scale's reliability, CFA to examine the rationality of the expected model, and multiple regression analysis to test the hypotheses. 
Yi Peng, Liang-ru Yu and Dong-xue Xie

\subsection{Reliability and validity}

Cronbach's $\alpha$ coefficient of the four variables (usefulness, trust, security, and information adoption) can be calculated through SPSS 22.0, which is $0.618,0.701,0.765$ and 0.672 respectively. Hair, et al. [26] noted that, when the measure indices of variable are less than 6 , the scale is reliable on the premise of $\alpha>0.6$, while it is acceptable in exploratory researches even if $\alpha>0.5$. Therefore, the scale is equipped with relatively satisfying internal consistency reliability. Confirmatory Factor Analysis (CFA) results show that all the fit indexes are acceptable. The standard factor loading achieves comparatively high significance level $(\mathrm{p}<0.01)$, and manifests comparatively good convergent validity. The 95\% confidence interval of the pairwise-related coefficients between factors does not contain 1 or -1 ; therefore, it has good discriminate validity.

There is a significant difference between the fitting result of Harman single-factor model and the fitting result of the four factors model, which implies that not all factors can be explained by one latent variable. Thus, common method variance bias is not serious.

In addition, variance inflation factors (VIF) of each variable in all of the models are far less than 10, which imply that there is no serious multicollinearity among variables, and the analysis result is reliable. Following the common method, we have used the mean value of scores gotten from the items' subordinating variables to represent the scores gained by variables.

Simultaneously, following the common method, we centralize the variables scores (subtracting the mean value of variables) to reduce the multicollinearity effect, before calculating interaction terms [27]. Table 1 shows the mean values, standard deviations, and correlation coefficients of variables.

Table 1: Mean, standard deviation and correlation

\begin{tabular}{|c|c|c|c|c|}
\hline Variables & $\mathbf{1}$ & $\mathbf{2}$ & $\mathbf{3}$ & $\mathbf{4}$ \\
\hline 1. Information Adoption & 1 & & & \\
\hline 2. Usefulness & $.595^{* *}$ & 1 & & \\
\hline 3. Trust & $.377^{* *}$ & $.577^{* *}$ & 1 & \\
\hline 4. Security & $.259^{* *}$ & $.400^{* *}$ & $.678^{* *}$ & 1 \\
\hline Mean Value & 4.027 & 3.910 & 3.497 & 3.395 \\
\hline Standard Deviation & .568 & .583 & .692 & .774 \\
\hline
\end{tabular}

Note. ${ }^{*} \mathrm{p}<0.05, * * \mathrm{p}<0.01$.

\section{Hypothesis testing}

\subsection{Main effect}

Usefulness has a positive impact on information adoption $(\beta=0.528, \mathrm{p}<0.01)$. Trust has a non-significant impact on information adoption $(\beta=0.037, p>0.05)$. Security has a nonsignificant impact on information adoption $(\beta=0.042, \mathrm{p}>0.05)$. Thus, H1 is supported, while $\mathrm{H} 2$ and $\mathrm{H} 3$ are not. 
Research on Information Adoption Behavior in Virtual Communities Based on the Information Ecology Theory

\subsection{Interaction effect}

The interaction of usefulness and trust has a non-significant impact on information adoption behavior $(\beta=-0.065, \mathrm{p}>0.05)$. The interaction of usefulness and security has a non-significant impact on information adoption behavior $(\beta=0.068, p>0.05)$. The interaction of trust and security has a positive impact on information adoption behavior $(\beta=0.114, \mathrm{p}<0.05)$. Only H6 is supported, while H4, and H5 are not. Table 2 presents the hypothesis testing, and the results are shown in Figure 1.

Table 2: Hypothesis testing

\begin{tabular}{|c|c|c|c|}
\hline \multirow[t]{2}{*}{ Variables } & \multicolumn{3}{|c|}{$\begin{array}{l}\text { Dependent Variable: } \\
\text { Information Adoption }\end{array}$} \\
\hline & Model 1 & Model 2 & Model 3 \\
\hline Age & -.046 & .017 & .017 \\
\hline $\begin{array}{c}\text { Education } \\
\text {-Bachelor Bellow }\end{array}$ & -.172 & -.167 & -.174 \\
\hline $\begin{array}{c}\text { Education } \\
\text {-Master or Above }\end{array}$ & -.072 & -.059 & -.063 \\
\hline $\begin{array}{c}\text { Occupation } \\
\text {-Education and Research } \\
\text { Development }\end{array}$ & -.050 & -.031 & -.032 \\
\hline $\begin{array}{c}\text { Occupation } \\
\text {-Institutional and Other Organizations }\end{array}$ & .096 & .042 & .031 \\
\hline Usefulness & & .555 & $.528 * *$ \\
\hline Trust & & .064 & .037 \\
\hline Security & & -.013 & .042 \\
\hline Usefulness $x$ Trust & & & -.065 \\
\hline Usefulness $\times$ Security & & & .068 \\
\hline Trust $\times$ Security & & & $.114 *$ \\
\hline $\mathrm{R}^{2}$ & .048 & .387 & .407 \\
\hline $\mathrm{F}$ & $4.012^{* *}$ & $30.906^{* *}$ & $24.252^{* *}$ \\
\hline$\Delta \mathrm{R}^{2}$ & .048 & .338 & .020 \\
\hline $\mathrm{F}$ of $\Delta \mathrm{R}^{2}$ & $4.012^{* *}$ & $72.117^{* *}$ & $4.379^{* *}$ \\
\hline Maximum VIF Value & 1.058 & 2.347 & 2.460 \\
\hline
\end{tabular}

Note. $* \mathrm{p}<0.05, * * \mathrm{p}<0.01$. 
Yi Peng, Liang-ru Yu and Dong-xue Xie

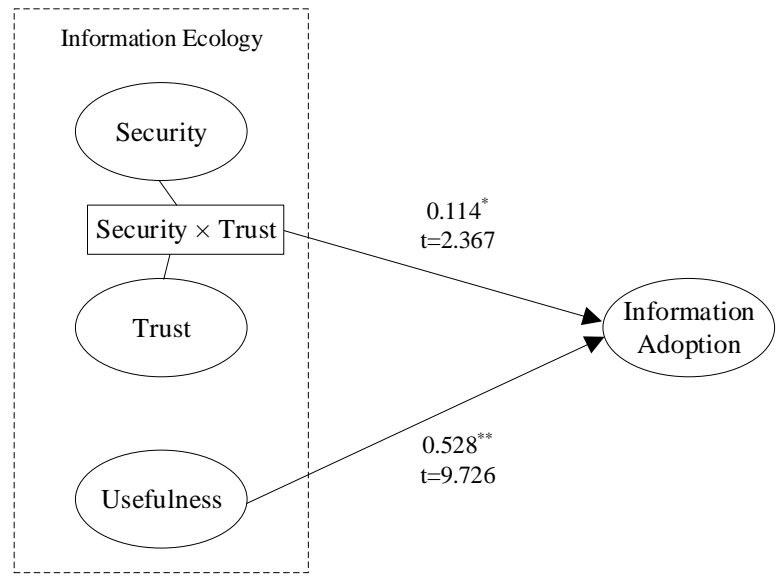

Figure 1: Research results

\section{Conclusion}

Based on the information ecology theory, this paper built a research model in virtual communities. Using data collected through 401 surveys in virtual communities, we empirically tested the hypotheses. The main conclusions are as follows: firstly, usefulness has a positive impact directly on information adoption, while trust and security show no significant impacts on it. The reason may be that the more valuable the action of an individual is to him or her, the more likely he or she is to take the action [28]. The value of information adoption mainly reflects in the value of its information, while trust and security only influence the reliability and safety of the information, rather than directly embody the value of the information. Usefulness of information can bring information value to users and make them better comprehend information, utilize it, and benefit from it. Therefore, usefulness can enhance their information adoption behaviour. Secondly, the interaction of trust and security has a positive influence on information adoption, while the remaining two interactions (usefulness and trust, usefulness and security) have nonsignificant impacts on it. It shows that the interaction of trust and security has a stronger influence on information adoption than that of the other two interactions.

The theoretical significance provided in this research includes two aspects: On one hand, this paper focuses on virtual communities, and it analyzes users' information adoption based on information ecology theory. On the other hand, this paper researches users' information adoption behavior, focusing on the main effects and the interaction effects of the influencing factors, which is supported by the empirical study.

In this paper, the empirical results indicate that the virtual community's managers should pay attention to users' information adoption, which are influenced by many factors. In the process of their conducting architecture designs, function settings, and system improvements in the virtual community, there is a need to adjust relationships between the different factors, and to enforce the construction of the virtual community in order to support users' behaviors and promote the development of the virtual community.

Limitations of the study and future directions in this paper include: in the setting of the variable, there is a lack of consideration to information, information man, and 
Research on Information Adoption Behavior in Virtual Communities Based on the Information Ecology Theory

information environment. To open and diverse virtual communities, these three main elements are influenced by many factors. This paper only selects the most important one as a variable from the factors influencing the three main elements, respectively.

Meanwhile, its measurement of the variable only reflects users' subjective willingness to adopt information in virtual communities. Therefore, in future investigations, we could collect the data of users' real behaviors in virtual communities (for example, access numbers, reply numbers, collection numbers, etc.) to proceed with objective verification. Besides, because different types of virtual communities will have different influences on information adoption, future research may focus on one type of virtual community (such as a learning community, an interesting community, a transaction community, etc.) to carry out a targeted study on information adoption.

Acknowledgements. This work is supported Chongqing University of Posts and Telecommunications Undergraduates' Scientific Research Training Program in 2015, "Information searching and knowledge sharing behavior of network users".

\section{REFERENCES}

1. K.Y.Yang, Research on information ecosystem construction about e-business, Information Sciences, 32(3) (2014) 37-42.

2. B.A.Nardi and V.L.O'day, Information Ecologies: Using Technology with Heart, MIT Press, Cambridge, 1999.

3. X.S.Chen and J.R.Yuan, Research of the information system elements of enterprise information resource ecological system, Technology Economics, 7 (2002) 21-22.

4. S.Chen, Information ecological imbalance and balance, Information and Documentation Services, 4 (2002) 12-13.

5. L.Q.Jiang, Information Ecology and Social Sustainable Development, Beijing Library Press, Beijing, 2003.

6. C.M.Chiu and E.T.G.Wang, Understanding knowledge sharing in virtual communities: An integration of social capital and social cognitive theories, Decision Support Systems, 42 (2006) 1872-1887.

7. M.H.Hsu, J.C.H.Yen and C.M.Chang, Knowledge sharing behavior in virtual communities: The relationship between trust, self-efficacy, and outcome expectations, International Journal of Human-Computer Studies, 65(2) (2007) 153169.

8. X.Jiang, The review of the influencing factors of virtual community information sharing behavior, Research on Library Science, 10 (2014) 18-24.

9. C.M.K.Cheung, M.K.O.Lee and N.Rabjohn, The impact of electronic word-ofmouth: The adoption of online opinions in online customer communities, Internet Research, 18(3) (2008) 229-247.

10. X.Y.Song and P.Wang, Research on concept and effective factors of information adoption behavior, Information Sciences, 28(5) (2010) 760-767.

11. B.Shi and H.Y.Mao, Research on the influence factors of social media users' information adoption behavior under public crisis, Information Sciences, 34(8) (2016) 36-41. 
Yi Peng, Liang-ru Yu and Dong-xue Xie

12. D.D.Xiang, Y.N.Yi and X.H.Fan, The research on the impact of perceived information quality to information adoption attitude, Information Sciences, 34(7) (2016) 86-90.

13. K.Y.Lee and S.B.Yang, The role of online product reviews on information adoption of new product development professionals, Internet Research, 25(3) (2015) 435-452.

14. R.Cheung, The influence of electronic word-of-mouth on information adoption in online customer communities, Global Economic Review, 43(1) (2014), 42-57.

15. A.Nguyen and M.Western, Socio-structural correlates of online news and information adoption/use: Implications for the digital divide, Journal of Sociology, 43(2) (2007) 167-185.

16. X.W.Wang, M.Q.Yang and Y.F.Xing, Construction and empirical research of the ecological evaluation index for WAP portal: Analysis based on information ecology perspective, Information Studies: Theory \& Application, 38(6) (2015) 14-18.

17. T.Mayayisw and O.I.Olusegun, E-commerce assurance models and trustworthiness issues: An empirical study, Journal of Information Management \& Computer Security, 22(1) (2014), 76-96.

18. J.Zhang and R.A.Cohen, Framework for trust modeling in multiagent electronic marketplaces with buying advisors to consider varying seller behavior and the limiting of seller bids, ACM Trans on Intelligent Systems and Technology, 4(2) (2013) 1-33.

19. X.Y.Song, Research on Construction and Application of User Information Adoption Behavior Model, Jilin University, Changchun, 2010.

20. D.Gefen, E.Karahanna and D.Straub, Trust and TAM in online shopping: An integrated model, MIS Quarterly, 27(1) (2003) 51-90.

21. S.X.Luo, Research of WOM Communication Effect on Purchase Decision: the Case of College Students, Zhejiang University, Hangzhou, 2007.

22. X.W.Wang, M.Q.Yang, W.X.Zhang and Y.Guo, Evaluation of the ecology of the enterprise information portal: Analysis based on the perspective of customer experience, Library and Information Service, 58(4) (2014) 46-52.

23. L.Hsu and Z.Walter, Search engine or content website? A local information seeking classification model based on consumer characteristics and website perceptions, International Journal of Human-Computer Interaction, 31 (2015) 263-276.

24. Z. Seyedghorban, H.Tahernejad and M.J. Matanda. Reinquiry into advertising avoidance on the Internet: A conceptual replication and extension, Journal of Advertising, 45 (2016) 120-129.

25. R. Palanisamy, The impact of privacy concerns on trust, attitude and intention of using a search engine: An empirical analysis, International Journal of Electronic Business, 11 (2014) 274-296.

26. J.F.Hair, R.E.Anderson, R.L.Tatham and W.C.Black, Multivariate Data Analysis, Prentice Hall, New Jersey, 1998.

27. L.S.Aiken and S.G.West, Multiple Regression: Testing and Interpreting Interaction, CA: Sage, Newbury Park, 1998.

28. R.M.Emerson, Social exchange theory, Annual Review of Sociology, 2 (1976) 335362. 